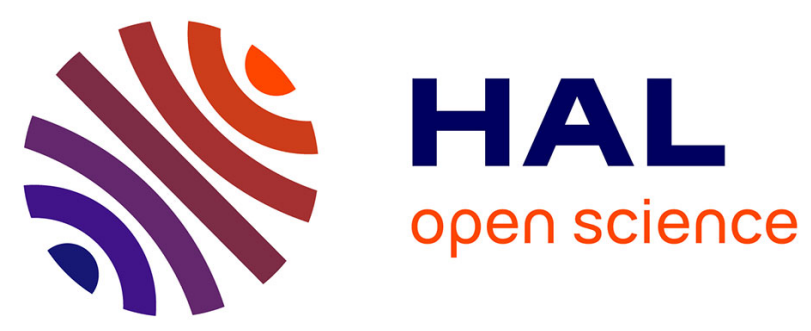

\title{
Conversion During Laparoscopic Adrenalectomy for Pheochromocytoma: A Cohort Study in 244 Patients
}

Marie Laure Schweitzer, Phi-Linh Nguyen-Thi, Eric Mirallie, Meno Vriens, Marco Raffaelli, Marc Klein, Rasa Zarnegar, Laurent Brunaud

\section{- To cite this version:}

Marie Laure Schweitzer, Phi-Linh Nguyen-Thi, Eric Mirallie, Meno Vriens, Marco Raffaelli, et al.. Conversion During Laparoscopic Adrenalectomy for Pheochromocytoma: A Cohort Study in 244 Patients. Journal of Surgical Research, 2019, 243, pp.309-315. 10.1016/j.jss.2019.05.042 . hal03484642

\section{HAL Id: hal-03484642 \\ https://hal.science/hal-03484642}

Submitted on 21 Dec 2021

HAL is a multi-disciplinary open access archive for the deposit and dissemination of scientific research documents, whether they are published or not. The documents may come from teaching and research institutions in France or abroad, or from public or private research centers.
L'archive ouverte pluridisciplinaire HAL, est destinée au dépôt et à la diffusion de documents scientifiques de niveau recherche, publiés ou non, émanant des établissements d'enseignement et de recherche français ou étrangers, des laboratoires publics ou privés.

\section{(ㅇ)(1) $\$$}

Distributed under a Creative Commons Attribution - NonCommerciall 4.0 International 


\section{CALIBRATING AND MEASURING WAKES AND DRAG FORCES OF INLAND VESSELS IN CONFINED WATER IN A TOWING TANK.}

Clément Caplier, Guillaume Gomit, Germain Rousseaux, Damien Calluaud, Ludovic Chatellier and Laurent David, Institut Pprime, CNRS - University of Poitiers - ISAE-ENSMA, France.

\section{SUMMARY}

This paper gives a review of the experimental methods developed in the towing tank of the Pprime Institute of the University of Poitiers, France, for the characterization of ship wakes and drag forces in confined waters. Different waterway configurations in calm water and in the presence of a current are reproduced in the experimental facility and small scale ship models of different block coefficients are considered. Stereoscopic optical methods have been developed in the laboratory for the measurement of the free surface deformation around the ship. The full wake generated by the ship is fully characterized and its hydraulic and undulatory properties are analyzed in both real space and spectral domain. In addition, a system for the measurement of the ship drag force has been set up and visualizations of the wakes have been performed in parallel with a highspeed camera, to relate the ship resistance crisis with its visual footprint in the wake.

\section{NOMENCLATURE}

$\alpha_{\mathrm{b}}$

$A_{\text {FFT }}$

$A_{1}$

$A_{2}$

B

$C_{\mathrm{b}}$

$C_{\mathrm{d}}$

D

$F_{\text {h1 }}$

$F_{\text {h2 }}$

$F_{\mathrm{h}, \mathrm{s}}$

$F_{\text {L, }}$

$F_{\mathrm{X}}$

$g$

H

h

$h_{\mathrm{b}}$

$h_{\text {bottom }}$

I

$k_{\mathrm{x}, \mathrm{y}}$

$L_{\mathrm{S}}$

$L_{\mathrm{c}}$

$L_{1}$

$L_{2}$

$\lambda_{\mathrm{t}, 1}$

$\lambda_{\mathrm{t}, 2}$

m

$\rho$

$S_{\mathrm{W}}$

$U_{\mathrm{s}}$

$u_{\mathrm{c}}$

$u_{\mathrm{r}}$

W
Banks inclination angle $\left(^{\circ}\right)$

Normalized amplitude of the Fast Fourier

Transform of the ship wake (-)

Normalized amplitude of the transverse waves in calm water (-)

Normalized amplitude of the transverse waves in counter-current (-)

Beam (width) of the ship hull (m)

Block coefficient of the ship hull (-)

Drag coefficient of the ship hull (-)

Draft of the ship hull (m)

Critical Froude number (sub. $\rightarrow$ trans.) (-)

Critical Froude number (trans. $\rightarrow$ sup.) (-)

Froude-depth number of the ship (-)

Froude-length number of the ship (-)

Axial component of ship resistance $(\mathrm{N})$

Gravitational acceleration $\left(\mathrm{m} . \mathrm{s}^{-2}\right)$

Height of the ship hull (m)

Water depth (m)

Height of the inclined bank (m)

Height of the double bottom (m)

Expanded uncertainty $(k=2)$ of the ship resistance measurement $(\mathrm{N})$

Wavenumber along the $x$ (longitudinal) or $y$ (transversal) axis $\left(\mathrm{m}^{-1}\right)$

Length of the ship (m)

Length of the canal $(\mathrm{m})$

Normalized length of the wash zone in calm water (-)

Normalized length of the wash zone in counter-current (-)

Normalized wavelength of the transverse waves in calm water (-)

Normalized wavelength of the transverse waves in counter-current (-)

Blockage ratio of the waterway (-)

Density of water $\left(\mathrm{kg} / \mathrm{m}^{3}\right)$

Wetted surface area of the ship $\left(\mathrm{m}^{2}\right)$

Ship speed $\left(\mathrm{m} . \mathrm{s}^{-1}\right)$

Velocity of the river current $\left(\mathrm{m} \cdot \mathrm{s}^{-1}\right)$

Velocity of the return current $\left(\mathrm{m} . \mathrm{s}^{-1}\right)$

Large width of the waterway (m)

$\begin{array}{ll}w & \text { Small width of the waterway }(\mathrm{m}) \\ w_{\mathrm{b}} & \text { Width of the inclined bank }(\mathrm{m}) \\ X & \text { Longitudinal dimension of the wake }(\mathrm{m}) \\ \Delta X & \text { Spatial resolution along the } \mathrm{X} \text { axis }(\mathrm{m}) \\ Y & \text { Transversal dimension of the wake }(\mathrm{m}) \\ \Delta Y & \text { Spatial resolution along the } \mathrm{Y} \text { axis }(\mathrm{m}) \\ Z & \text { Vertical dimension of the wake }(\mathrm{m}) \\ \Delta Z & \text { Spatial resolution along the } \mathrm{Z} \text { axis }(\mathrm{m})\end{array}$

\section{INTRODUCTION}

When a ship progresses in a confined waterway, such as a river, a canal or an estuary, it faces an increase in the advancing resistance and also experiences various phenomena in the waterway. There is a lowering of the water level, combined with the generation of a return current around the ship hull. The waves generated in its wake interact with the current of the waterway and reflect on the river banks, causing erosion and sediment transport issues. To prevent their appearance in the waterway, for both economical (reduce fuel consumption) and ecological (reduce bank erosion) reasons, many numerical studies are performed (Linde et al., 2017; Pacuraru and Domnisoru, 2018; Razgallah et al., 2018; Terziev et al., 2018). However, the specific properties of the confined water wakes are not completely described numerically or theoretically. Experimental investigations are still necessary to understand the generation and the propagation of the waves and the flow with respect to the functional and geometrical parameters of the ship and the waterway. This path of research has been investigated in the past few years by the Hydrodynamic and Environmental Flows team of the Pprime Institute of the University of Poitiers in France. A configuration of confined waterway with a presence of current has been reproduced in the towing tank of the laboratory. Several experimental methods have been developed for the measurement of the ship resistance, the characterization of the return current around the hull, the study of the wave reflections and the full-field characterization of the generated ship wake. To investigate the properties of the waves generated by the hulls, a fine characterization of the free surface is indispensable to lead the analysis in the spectral domain. On the basis of the theory of the waves generated by a uniformly moving source established by (Ekman, 
1906) and (Crapper, 1964) and the recent review of the geometrical properties of the emitted patterns in the real and spectral spaces by (Carusotto and Rousseaux, 2013), a spectral analysis method of ship wakes has been developed. Such spectral analysis methods have been proposed by (McKenzie, 1970) and (Lighthill, 1979). (Griffin et al., 1996) and (Arnold-Bos et al., 2007) have used them to estimate the velocity of a ship or the shape of its hull from synthetic aperture radar (SAR) images or high resolution optical images of the wake. However, these methods have never been validated experimentally in the field of ship wakes measured in the laboratory. In the first part of the paper, the waterway configuration set up in the towing tank of the Pprime Institute is presented and the small scale ship models representative of maritime and river ships are introduced. In the second part, the experimental measurement methods are detailed and the spectral analysis method is detailed. Then, the main results of the studies are presented and finally research perspectives will be exposed with the future project of development of the canal.

\section{THE TOWING TANK AND THE SHIP MOD- ELS}

\subsection{THE WATERWAY}

Figure 1 represents the cross-section of the towing tank of the Pprime Institute. It is composed of a bottom trapezoidal section of small width $w=1.10 \mathrm{~m}$ and large width $W=1.50 \mathrm{~m}$, and a top rectangular section of same width. The inclination of the banks is $\alpha_{\mathrm{b}}=45^{\circ}$ and their width and height are $w_{\mathrm{b}}=h_{\mathrm{b}}=0.20 \mathrm{~m}$. A double bottom of height $h_{\text {bottom }}=0.38 \mathrm{~m}$ can be installed in the towing tank to reduce the water depth to reproduce a shallow waterway of rectangular cross-section of depth $h$. The water depth has been set up to $h=0.103 \mathrm{~m}$ for the experiments. The rail mounted towing carriage displaces the ship hull at a speed $U_{\mathrm{s}}$ up to $2.35 \mathrm{~m} . \mathrm{s}^{-1}$ along the canal of length $L_{\mathrm{c}}=20 \mathrm{~m}$. The double-bottom gives also the possibility to generate a current by placing a circulator in the lower section, and two honeycombs structures at the extremities of the canal to laminarize the flow. The current can be generated in both directions with respect to the ship motion (co- or counter-current). The canal is equipped with bottom and lateral windows to perform optical measurements and visualizations.

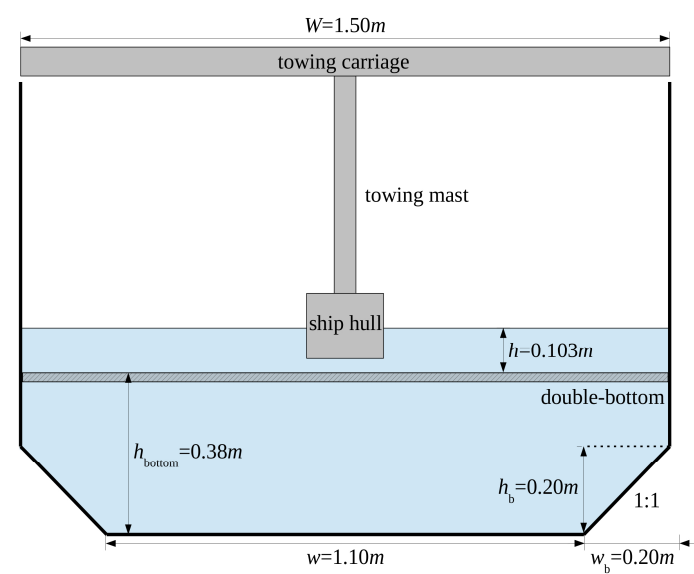

Figure 1. Transversal section of the towing tank.

\section{2}

\section{THE SMALL SCALE SHIP MODELS}

In order to compare the experimental results with numerical calculations of ship wakes and ship resistance, two generic ship hulls of parabolic shape have been considered. They are based on the Wigley (1926) hull form with a rectangular cross-section, mathematically defined by Eq. (1) with $n=2$ for a classical Wigley hull:

$y=f(x)=\frac{B}{2}\left[1-\left(\frac{2 x}{L_{S}}\right)^{n}\right]$

As the block coefficient of such a Wigley hull is $C_{\mathrm{b}}=0.67$, another Wigley-based ship hull with an exponent $n=8$, giving a block coefficient $C_{\mathrm{b}}=0.89$, has been considered (Caplier et al., 2016). These two ship hulls noted WH2 and WH8 because of their $n$-coefficients are then representative of maritime and river ships in terms of block coefficients. The ship hulls dimensions are $L_{\mathrm{s}}=1.20 \mathrm{~m}, \quad B=0.18 \mathrm{~m}$ and $H=0.15 \mathrm{~m}$, and their draft is set-up to $D=0.075 \mathrm{~m}$ for the experiments. They are shown on Figure 2. As regards the effects of scale, the ship speeds for the experiments are set high enough to avoid capillary effects (less than 5\%). In this range of ship speeds, the effects of the scale on the flow characteristics are limited (Gomit et al., 2015).

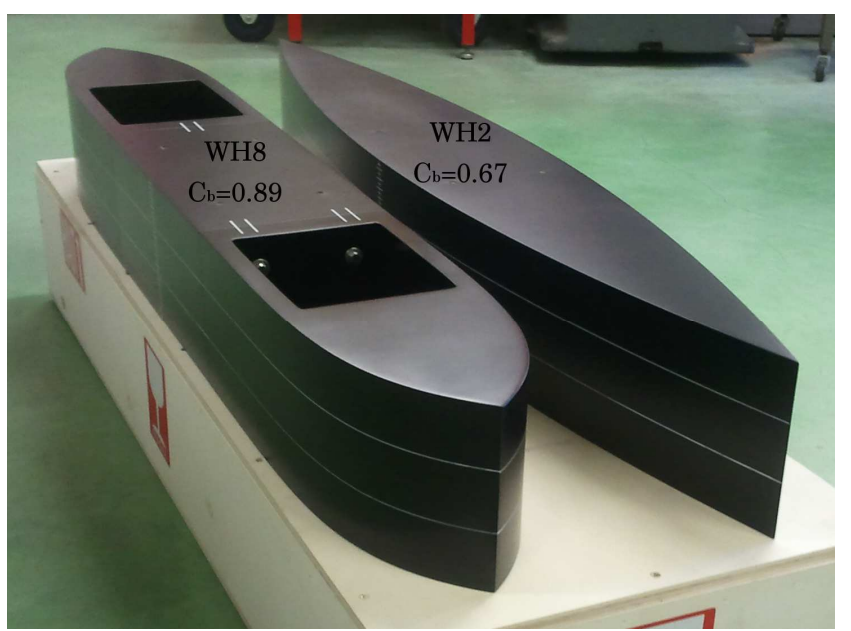

Figure 2. The WH8 and WH2 ship hulls.

\section{THE MEASUREMENT AND THE ANALYSIS OF THE SHALLOW WATER SHIP WAKE}

\subsection{MEASUREMENT OF THE FREE SURFACE DE- FORMATION}

The free surface deformation is measured with a stereoscopic measurement method, based on the principle of refraction of light rays through the surface of water that is developed in our laboratory (Gomit et al., 2013). The setup is represented on Figure 3. It is composed of two Dantec SpeedSense 1040 cameras that deliver a resolution of 2320x1726 px, mounted with Nikkor AF $28 \mathrm{~mm}$ 1:2.8 lenses. They focus on the same zone with an opposite angle of $\pm 15^{\circ}$ with respect to the longitudinal axis of the canal, and $\pm 35^{\circ}$ with respect to the vertical axis. The common field covered by the cameras forms a rectangle of dimensions 
$0.75 \times 0.90 \mathrm{~m}^{2}$, corresponding to the half width of the canal. The stereoscopic system is calibrated by translating a dotted calibration plate and using a distortion model. A specklepattern is placed at the bottom of the canal and its image with the water surface at rest is recorded on the cameras for the reference. Then the ship is launched and the images of the pattern, deformed by the free surface deformations, are recorded on both cameras at a frequency of 10 frames per second with an exposure time of $10 \mathrm{~ms}$. Each run is performed three times to check the repeatability of the measurement. The image pairs are then processed with a reconstruction algorithm written in $\mathrm{C}++$ and based on the SLIP library (Tremblais et al., 2010) that computes the free surface deformation at each time-step. Then the whole wake is reconstructed around the ship hull with a dedicated reconstruction program, with a spatial resolution $\Delta X=\Delta Y=10 \mathrm{~mm}$ and a precision $\Delta Z=0.1 \mathrm{~mm}$ on the water level.

\subsection{ANALYSIS IN THE REAL SPACE}

An example of the wakes measured in calm water and in the presence of a counter-current with the stereo-refraction measurement method are shown on Figure 4 (Caplier et al., 2015). These wakes are generated by the WH2 hull for a ship speed $U_{s}=0.45 \mathrm{~m} . \mathrm{s}^{-1}$ and a water depth $h=0.103 \mathrm{~m}$, giving a Froude-depth number $F_{\mathrm{h}, \mathrm{s}}=U_{\mathrm{s}} /(g h)^{1 / 2}=0.45$ and a

\section{Lateral view :}

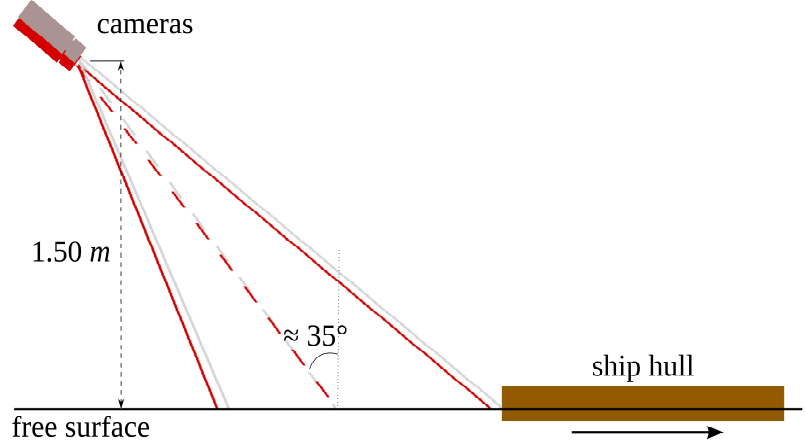

Froude-length number $F_{\mathrm{L}, \mathrm{s}}=U_{\mathrm{s}} /\left(g L_{\mathrm{s}}\right)^{1 / 2}=0.13$. The wake on the bottom of the figure is generated in a calm water configuration, whereas the top one is generated in the presence of a counter-current of velocity $u_{\mathrm{c}}=0.20 \mathrm{~m} . \mathrm{s}^{-1}$, corresponding to an effective Froude-depth number in the referential of the laboratory $F_{\mathrm{h}, \mathrm{s}}=\left(U_{\mathrm{s}}+u_{\mathrm{c}}\right) /(g h)^{1 / 2}=0.65$ (Caplier et al., 2015). A qualitative analysis of these wakes in the real space shows that the transverse wavelength and amplitude are increasing in the presence of the counter-current. The waves generated by the ship in its wake are convected by the current, that results in a widening of the wash zone at the banks of the canal. For a quantitative comparison of the wakes, longitudinal or transverse cuts can be made in the wave fields. Figure 5 represents the longitudinal cuts performed for the calm water and counter-current wakes. For the same ship speed, the length of the wash zone increases from $0.9 L_{\mathrm{s}}$ to $2 L_{\mathrm{s}}$ ( $L_{\mathrm{s}}=1.2 \mathrm{~m}$ is the ship length) with the counter-current, representing more than a doubling of its length. The transverse waves amplitude and wavelengths at the river banks respectively grows from $A_{1}=0.012 h$ to $A_{2}=0.059 h(h=0.103 \mathrm{~m}$ is the initial water depth), and from $\lambda_{\mathrm{t}, 1}=0.1 L_{\mathrm{s}}$ to $\lambda_{\mathrm{t}, 2}=0.3 L_{\mathrm{s}}$, an increase of nearly $500 \%$ of the amplitude and $30 \%$ of the wavelength.

Top view :

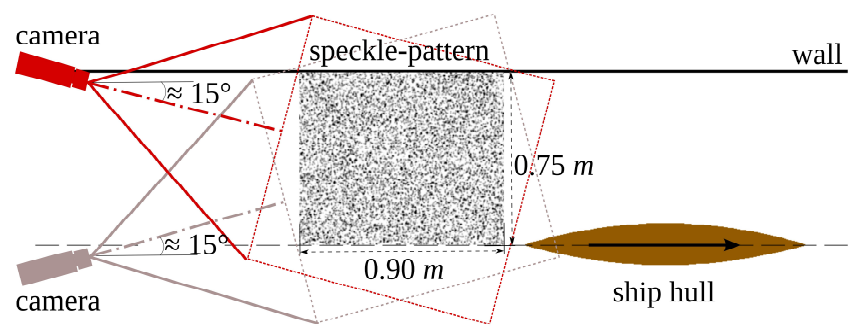
wall

Figure 3. Schematic representation of the experimental setup for the free surface measurement by stereo-refraction.

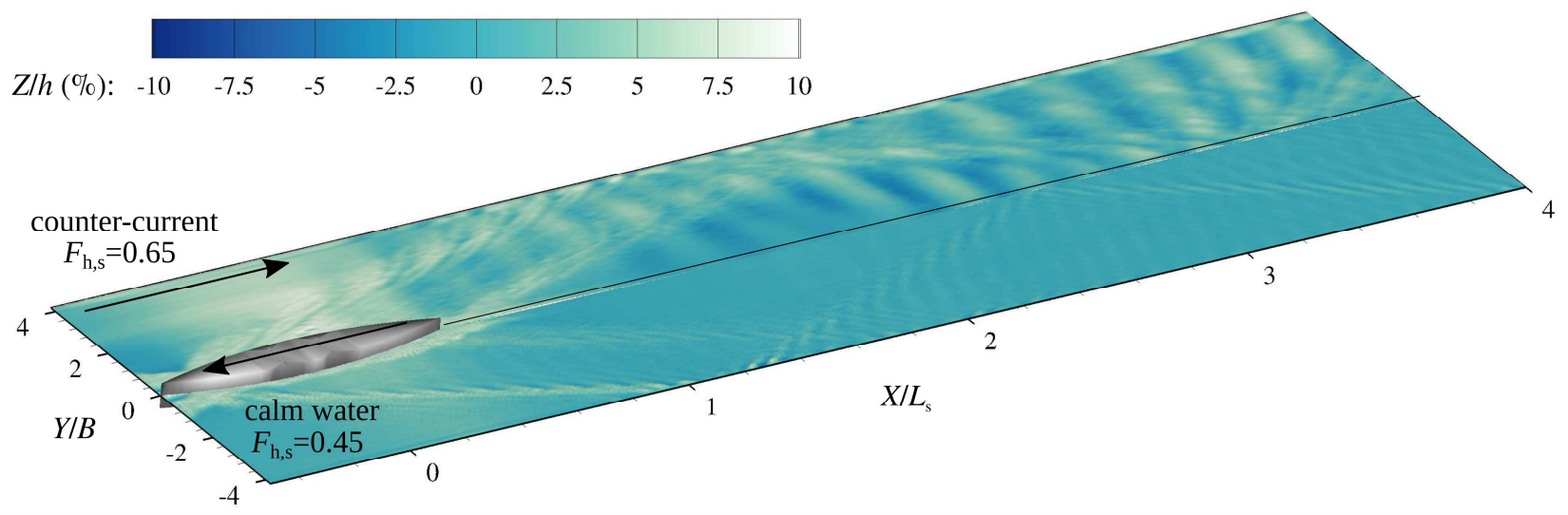

Figure 4. The wakes generated in calm water (bottom) and in the presence of a counter-current (top) by the WH2 hull, measured with the stereorefraction measurement method. 


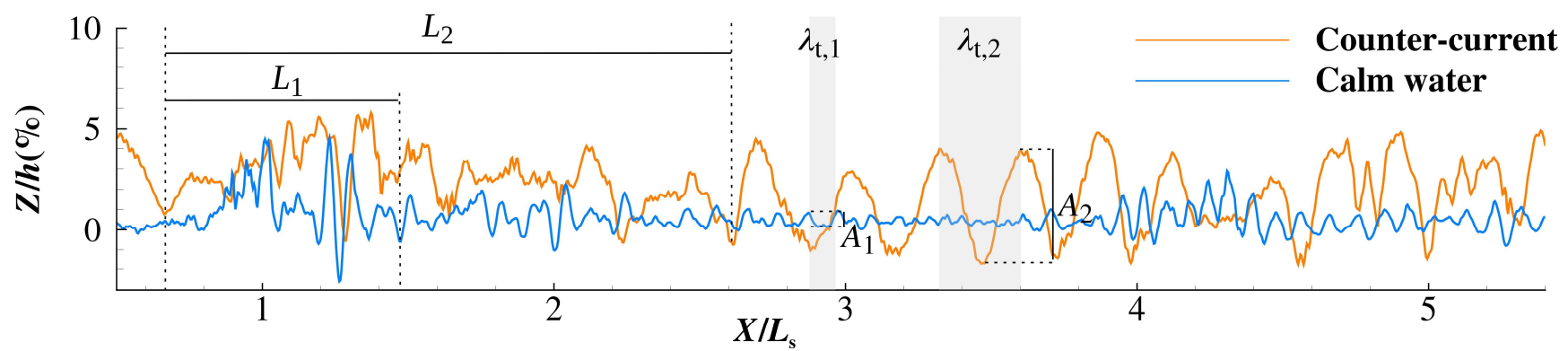

Figure 5. Longitudinal cuts in the wakes generated in calm water and in the presence of a counter-current at a transversal position $Y / B=3.5$. $\left(L_{1} ; A_{1} ; \lambda_{t, 1}\right)$ and $\left(L_{2} ; A_{2} ; \lambda_{t, 2}\right)$ represent respectively the width of the reflection zone, and the amplitude and the wavelength of the transverse waves, in calm water and in counter-current.

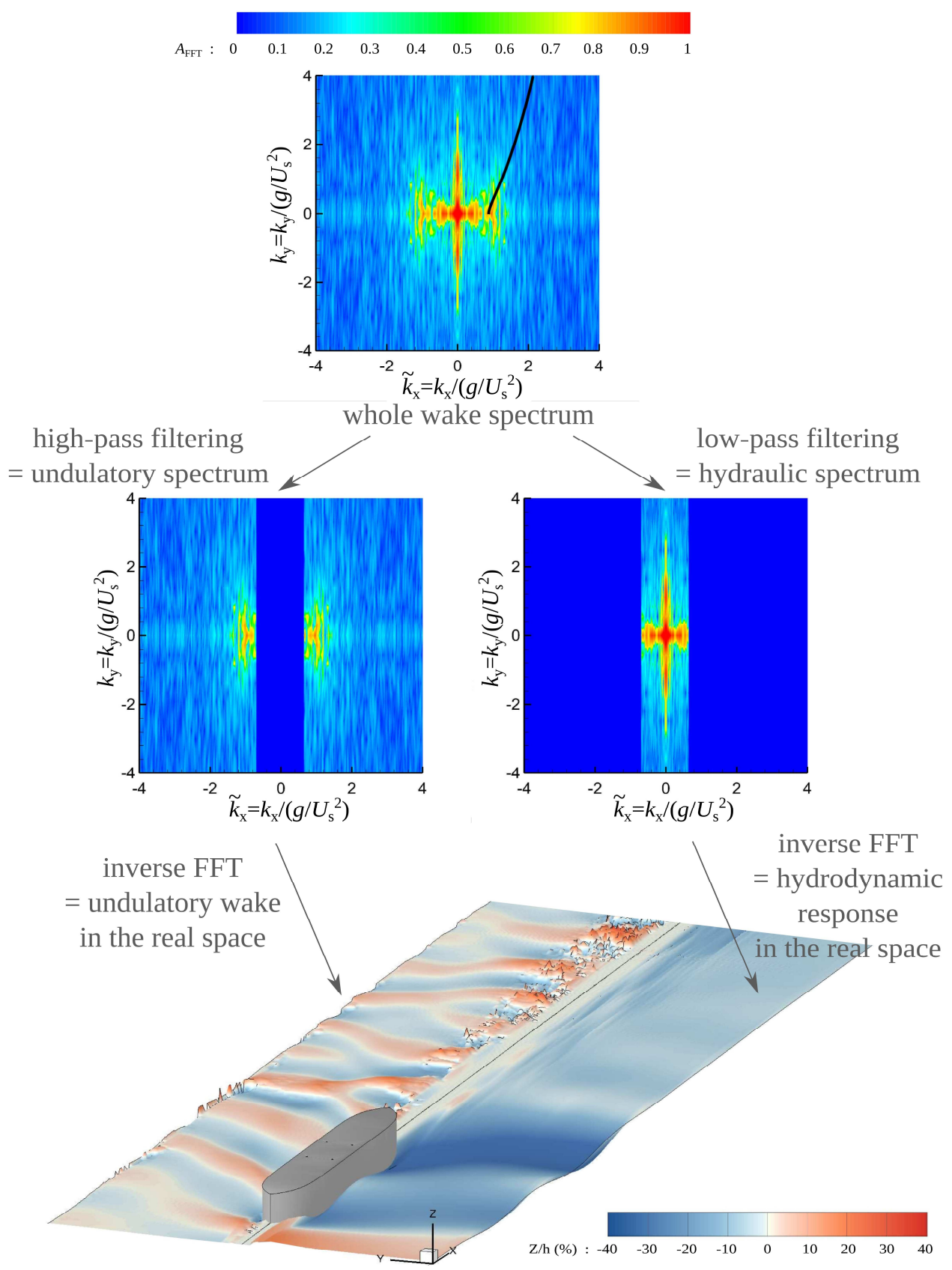

Figure 6. Spectral analysis of a ship wake. The top figure represents the spectrum of the wake generated by the WH8 hull in a calm and shallow water configuration for a Froude-depth number $F_{\mathrm{h}, \mathrm{s}}=0.80$ and a Froude-length number $F_{L, s}=0.23$. Then the spectrum is filtered to separate the hydraulic and undulatory components of the wake, which are reconstructed in the real space by computing the inverse bidimensional FFT. 


\subsection{SPECTRAL ANALYSIS OF SHIP WAKES}

The stereo-refraction measurement method gives a full, detailed and fine reconstruction of the ship wake. Then, it is possible to proceed the analysis in the spectral space by computing the bidimensional Fast Fourier Transform (FFT) of the wake. The method has been introduced by (Carusotto and Rousseaux, 2013), developed by (Gomit et al., 2014) for the analysis of ship wakes in deep water and then adapted by (Caplier et al., 2016) for the analysis of ship wakes generated in shallow water.

An example of the spectrum of the wake generated by the WH8 hull, for a ship speed $U_{\mathrm{s}}=0.80 \mathrm{~m} \cdot \mathrm{s}^{-1}$ and a water depth $h=0.103 \mathrm{~m}$, giving a Froude-depth number $F_{\mathrm{h}, \mathrm{s}}=U_{\mathrm{s}} /(g h)^{1 / 2}=0.80$ and a Froude-length number $F_{\mathrm{L}, \mathrm{s}}=U_{\mathrm{s}} /\left(g L_{\mathrm{s}}\right)^{1 / 2}=0.23$, is given on the right of Figure 6 (Caplier et al., 2016). The color on the spectrum represents the spectral repartition of the normalized amplitude of the FFT along the different wave lengths and directions in the wake. The high-pass or low-pass filtering of the spectrum and its reconstruction in the real space by computing an inverse bidimensional FFT allows to separate the hydraulic and undulatory components of the wake (Gomit et al., 2014) (Caplier et al., 2016).

\subsection{MEASUREMENT OF THE RETURN CURRENT}

The stereoscopic system can also be used to measure the return current generated around the hull, by computing the displacements of floating particles placed at the surface of the water. The images of these markers can then be processed by a stereo-PIV algorithm to calculate the flow velocity (Chatellier et al., 2013). The result is given on Figure 7 on which the return current is measured around the WH2 hull for a ship speed $U_{\mathrm{s}}=0.70 \mathrm{~m} \cdot \mathrm{s}^{-1}$ and a water depth $h=0.103 \mathrm{~m}$, giving a Froude-depth number $F_{\mathrm{h}, \mathrm{s}}=U_{\mathrm{s}} /(g h)^{1 / 2}=0.70$ and a Froude-length number $F_{\mathrm{L}, \mathrm{s}}=U_{\mathrm{s}} /\left(g L_{\mathrm{s}}\right)^{1 / 2}=0.20$. The return current is calculated in the whole field around the hull, it reaches its maximum of amplitude (30\% of the ship speed) at the middle of the hull, and extends along the whole width of the waterway. Then its direction alternates between the crests and troughs of the transverse waves, and its amplitude decreases slowly.

\section{THE SHIP RESISTANCE AND ITS VISUAL FOOTPRINT}

Resistance trials have been carried out in the towing tank of the Pprime Institute. The measurement of the ship drag force is performed with a Kistler 9272 multi-component dynamometer installed between the ship hull and the towing mast (Figure 8). The six-component piezoelectric sensor measures the axial forces in each direction as well as the torques. The ship resistance is taken as the axial force $F_{\mathrm{X}}$ opposed to the motion of the ship. The maximum measured amplitude is $F_{\mathrm{X}}=20 \mathrm{~N}$ and the uncertainty is $\mathrm{I}=0.80 \mathrm{~N}$ (Caplier, 2015). Then the non-dimensional drag coefficient $C_{d}$ can be derived with Equation 2, where $S_{\mathrm{w}}$ is the wetted surface area of the ship:

$C_{d}=\frac{F_{X}}{\frac{1}{2} \rho S_{w} U_{S}^{2}}$

Figure 9 represents the drag coefficients of the WH2 and WH8 hulls measured in a shallow water configuration $(h=0.103 \mathrm{~m})$ at different ship speeds (the Froude-depth number of the ship $F_{\mathrm{h}, \mathrm{s}}$ is between 0.60 and 1.31, and the Froude-length number of the ship $F_{\mathrm{L}, \mathrm{s}}$ is between 0.18 and 1.38). The evolution of the ship resistance is bounded by the critical Froude-depth numbers $F_{\mathrm{h} 1}$ and $F_{\mathrm{h} 2}$ calculated by Schijf's theory (Schijf, 1949). These critical Froude-depth numbers are calculated by Equations 3 and 4:

$F_{h 1}=\left[2 \sin \left(\frac{\arcsin (1-m)}{3}\right)\right]^{\frac{3}{2}}$
$F_{h 2}=\left[2 \sin \left(\frac{\pi-\arcsin (1-m)}{3}\right)\right]^{\frac{3}{2}}$

They depend on the blockage ratio $m$ (cross section of the ship to cross section of the canal). In the present experiments, $m=0.0874$. A sudden increase of the drag coefficient is observed for $F_{\mathrm{h}, \mathrm{s}}=\mathrm{F}_{\mathrm{h} 1}=0.64$ for both hulls. This increase referred as "the resistance crisis" appears at the boundary between the sub-critical and the transcritical regime. Finally, there is a decrease of the ship resistance at the entrance in the supercritical regime for $F_{\mathrm{h}, \mathrm{s}}=\mathrm{F}_{\mathrm{h} 2}=1.37$. Parallel visualizations have been made during the resistance trials, with a high-speed camera Photron Fastcam SA1 of resolution $1024 \times 1024 p x$ equipped with a Sigma $28 \mathrm{~mm}$ F1.8 DG ASP lens (Figure 8). The camera installed on the side of the canal, and captures images of the wave amplitudes at the window during the passage of the ship at a frequency of $125 \mathrm{fps}$. Then a dedicated algorithm assembles the images to give a picture-like representation of the wave amplitudes. Figure 10 represents the visualizations performed during the transition between the subcritical and transcritical regime (Froude-depth number $F_{\mathrm{h}, \mathrm{s}}$ from 0.60 to 0.85 and Froudelength number $F_{\mathrm{L}, \mathrm{s}}$ from 0.19 to 0.22 ). These visualizations highlight an increase of the transverse wavelength and amplitude at the boundary between the subcritical and transcritical regimes. A wave breaking is also visible on some waves. So when a ship navigates in a confined waterway, it experiences a sudden increase of its fuel consumption, and the waves that it generates grow, break and reflect on the river banks. That process is destructive for the river banks and needs to be investigated in a future work, to prevent its appearance and to design appropriate bank protections. 


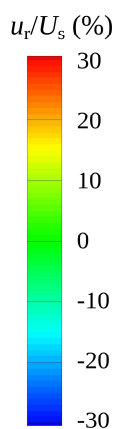

Figure 7. The return current $u_{\mathrm{r}}$ measured around the $\mathrm{WH} 2$ hull for a Froude-depth number $\boldsymbol{F}_{\mathrm{h}, \mathrm{s}}=\mathbf{0 . 7 0}$ with the stereocorrelation measurement method.

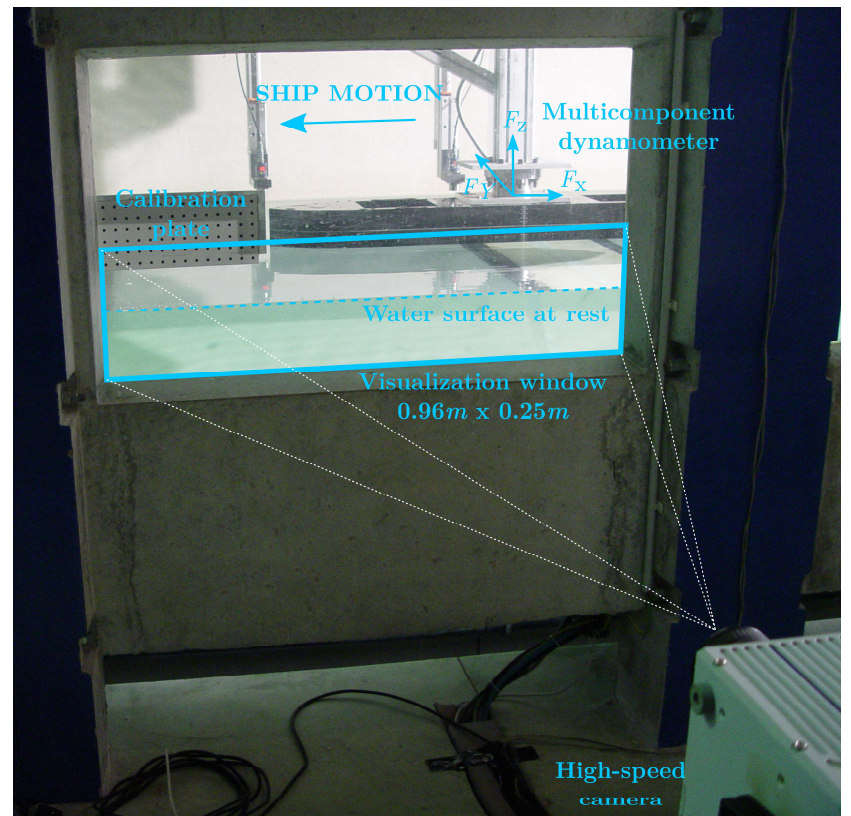

Figure 8. Measurement of the ship resistance with a multi-component dynamometer and lateral visualizations with a high-speed camera.

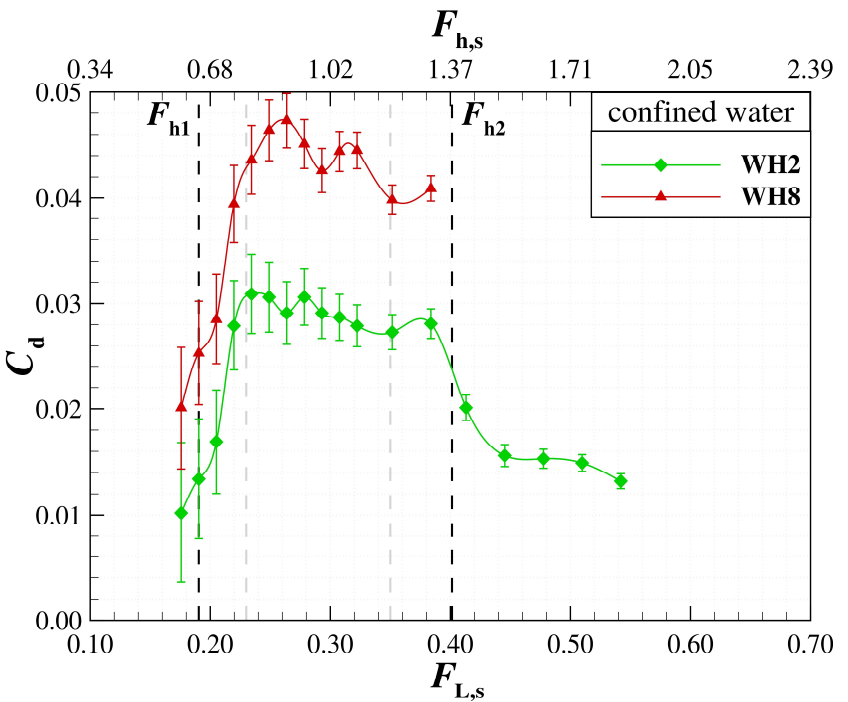

Figure 9. Drag coefficients of the ship hulls measured in a shallow water configuration for different ship speeds. The black dotted lines correspond to the critical Froude numbers $F_{h 1}=0.64$ and $F_{h 2}=1.37$ linked to the blockage of the waterway.

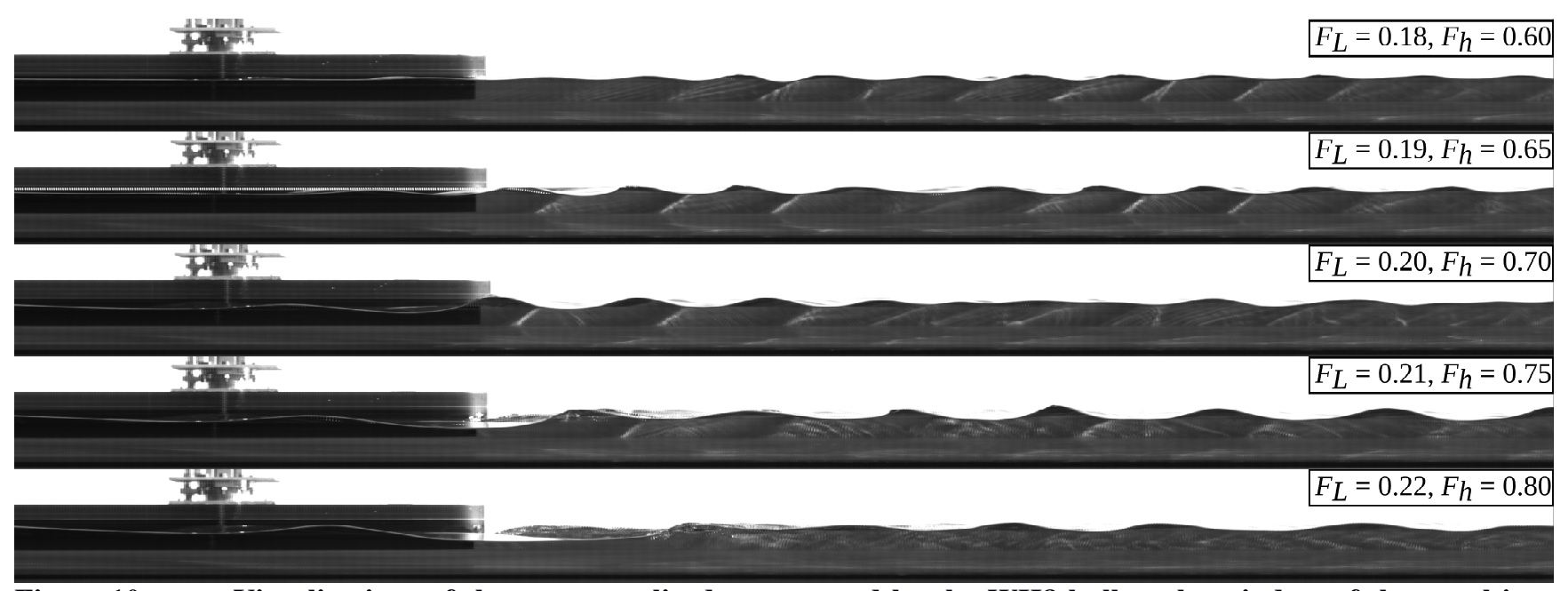

Figure 10. Visualizations of the wave amplitudes generated by the WH8 hull at the window of the canal in a shallow water configuration $(h=0.103 \mathrm{~m})$. Ship speed is increasing from the top to the bottom. 


\section{CONCLUSIONS AND PERSPECTIVES}

During the past few years, several experimental studies have been made in the towing tank of the Pprime Institute, to investigate the effects of confinement on ships wakes and drag and to understand interaction between the ship and the waterway. Measurement methods have been developed and adapted for this topic, to obtain a full and detailed measurement of the ship wake and to determine the drag forces applying on the hull. These methods give high quality results that allow to perform a fine analysis of the wave properties in both real and spectral spaces. The hydrodynamic effects appearing in the waterway can also be quantified and analyzed. The comparison of the resistance diagrams with the visualizations of the wakes allows to identify the visual footprint of the crisis of ship resistance. The towing tank of the Pprime Institute is currently under work, and will be lengthened of one third of its actual length, to reach $30 \mathrm{~m}$. The towing carriage and the current generation will also be improved. These great improvements on the facility will open the way to future experimental studies, in order to continue the investigations on this path of research.

\section{REFERENCES}

Arnold-Bos A., Martin A. and Khenchaf A., 2007. Obtaining a ship's speed and direction from its Kelvin wake spectrum using stochastic matched filtering. 2007 IEEE International Geoscience and Remote Sensing Symposium, Barcelona, 2007, pp. 1106-1109.

https://doi.org/10.1109/IGARSS.2007.4422995

Caplier C., 2015. Etude expérimentale des effets de hauteur d'eau finie, de confinement latéral et de courant sur les sillages et la résistance à l'avancement des navires. (In French). Phd Thesis, University of Poitiers, France, 2015. http://www.theses.fr/2015POIT2315/document

Caplier C., Rousseaux G., Calluaud D., David L., 2015. The effects of river counter-currents on ships wakes: an experimental approach, in: Proceedings of the AIPCN-SHF congress "Hydrodynamics and simulation applied to inland waterway and port approaches", Meudon, France.

Caplier C., Rousseaux G., Calluaud D., David L., 2019. Effects of finite water depth and lateral confinement on ships wakes and resistance. Journal of Hydrodynamics. https://doi.org/10.1007/s42241-019-0054-9

Caplier C., Rousseaux G., Calluaud D., David L., 2016. Energy distribution in shallow water ship wakes from a spectral analysis of the wave field. Physics of Fluids, 28(10):107104. https://doi.org/10.1063/1.4964923

Carusotto I., Rousseaux G., 2013. The Čerenkov effect revisited: from swimming ducks to zero modes in gravitational analogues. Lecture Notes in Physics Springer, 6:109144. https://doi.org/10.1007/978-3-319-00266-8_6 Chatellier L., Jarny S., Gibouin F., David L., 2013. A parametric PIV/DIC method for the measurement of free surface flows. Experiments in Fluids, 54(3):1-15. https://doi.org/10.1007/s00348-013-1488-4

Crapper G.D., 1964. Surface waves generated by a travelling pressure point. Proc. R. Soc. Lond. A, 282(1391):547558. https://doi.org/10.1098/rspa.1964.0250

Ekman V.W., 1906. On stationary waves in running water. Arkiv för Matematik, Astronomi och Fysik, 3(2).

Gomit, G. Chatellier, L. Calluaud, D., David, L., 2013. Free surface measurement by stereo-refraction. Exp. Fluids, 54(6):1-11. https://doi.org/10.1007/s00348-013-1540-4

Gomit, G. Rousseaux, G. Chatellier, L. Calluaud, D., David, L., 2014. Spectral analysis of ship waves in deep water from accurate measurements of the free surface elevation by optical methods. Physics of Fluids, 26:122101. http://dx.doi.org/10.1063/1.4902415

Gomit, G. Chatellier, L. Calluaud, D., David, L. Fréchou, D. Boucheron, R. Perelman, O. Hubert, C., 2015. Large scale free surface measurement for the analysis of ship waves in a towing tank. Experiments in Fluids, 56(10), 184. https://doi.org/10.1007/s00348-015-2054-z

Griffin O. M., Wang H. T., Meadows G. A., 1996. Ship hull characteristics from surface wake synthetic aperture radar (SAR) imagery, Ocean Engineering, 23(5):363-383. https://doi.org/10.1016/0029-8018(95)00042-9

Lighthill J., 1979. Waves in fluids, Cambridge University Press, Cambridge.

Linde F., Ouahsine A., Huybrechts N., Sergent P., 2017. Three-dimensional numerical simulation of ship resistance in restricted waterways: effect of ship sinkage and channel restriction. Journal of Waterway, Port, Coastal and Ocean Engineering, 43(1):06016003. https://doi.org/10.1061/(ASCE)WW.1943-5460.0000353

McKenzie J.F., 1970. Hydromagnetic wave interaction with the magnetopause and the bow shock. Planetary and Space Science, 18(1):1-23. https://doi.org/10.1016/00320633(70)90063-2

Pacuraru F., Domnisoru L., 2017. Numerical investigation of shallow water effect on a barge ship resistance. IOP Conference Series: Materials Science and Engineering, 227 012088 .

http://dx.doi.org/10.1088/1757-899X/227/1/012088

Razgallah I., Kaidi S., Smaoui H., Sergent P., 2019. The impact of free surface modelling on hydrodynamic forces for ship navigating in inland waterways: water depth, drift angle, and ship speed effect. Journal of Marine Science and Technology, 24(2):620-641.

https://doi.org/10.1007/s00773-018-0566-y

Schijf, J.B., 1949. Protection of embankments and bed in inland and maritime waters, and in overflow or weirs. In: 
Proceedings of the 17th International Navigation Congress, Lisbon, Portugal.

Terziev M., Tezdogan T., Oguz E., Gourlay T., Demirel Y.K., Incecik A., 2018. Numerical investigation of the behaviour and performance of ships advancing through restricted shallow waters. J. Fluid Struct., 76:185-215. https://doi.org/10.1016/j.jfluidstructs.2017.10.003

Tremblais B., David L. Arrivault D., Dombre J., Thomas L., Chatellier L., 2010. Standard Library for Image Processing, (Licence CECILL DL 03685-01, APPIDDN.FR.001.300034.000.S.P.2010.000.21000). http://sliplib.prd.fr/

Wigley, W.C.S., 1926. Ship wave resistance. A comparison of mathematical theory with experimental results. Trans. Inst. Naval Arch., 68:124-141.

\section{AUTHORS BIOGRAPHY}

Clément Caplier holds the current position of Postdoctoral Researcher at the University of Poitiers - Institut Pprime, France. He is specialized in optical measurement techniques for hydrodynamics. His previous experience includes an experimental thesis on the effects of finite water depth, lateral confinement and current on ships wakes and drag.

Guillaume Gomit holds the current position of Assistant Professor at the University of Poitiers - Institut Pprime, France. He obtained his PhD from the University of Poitiers in 2013 for his thesis on the optical measurement of ship waves in towing tanks. His research interests range from experimental hydrodynamic to rheology and transport of cohesive sediments.

Germain Rousseaux holds the current position of Senior Scientist at CNRS. He is a physicist doing interdisciplinary studies. His previous experience includes a $\mathrm{PhD}$ thesis on sand ripples formation with specializations on wave-current interactions (wave blocking, tidal bore...) and wake physics. $\mathrm{He}$ is interested with wave resistance theory and its applications to wash waves reduction by shapes optimization.

Damien Calluaud holds the current position of Assistant Professor at the University of Poitiers - Institut Pprime, France. He develops some stereoscopic and free surface measurements. His main interests are the ship waves, the bank erosion, the sediment transport and the ecohydraulics.

Ludovic Chatellier holds the current position of Assistant Professor the University of Poitiers - Institut Pprime, France. He is involved in renewable energy, hydrodynamics, ecohydraulics and optical metrology. His previous experience includes free-surface measurements, flow and wake analysis, development of energy harvesters and fish protection devices.
Laurent David is Professor of fluid mechanics in the university of Poitiers. He is at the head of the team HYDEE (Hydrodynamics and Environmental flows). Since twenty years, he develops 2D and 3D optical measurements (TRPIV, surface and volumic PIV). His research interests are free surface flows, turbulent and unsteady flows, fluid structure interactions and ecohydraulics. 
Table 1: Patient demographics and tumor characteristics

\begin{tabular}{|c|c|c|c|c|}
\hline & $\begin{array}{c}\text { Total } \\
(n=244)\end{array}$ & $\begin{array}{l}\text { No conversion } \\
(n=225)\end{array}$ & $\begin{array}{l}\text { Conversion } \\
\qquad(n=19)\end{array}$ & $\mathbf{p}$ \\
\hline Sex, Male, \% & $114(47)$ & $102(45)$ & $12(63)$ & 0.135 \\
\hline Age, years & $51+/-16$ & $50+/-16$ & $51+/-18$ & 0.825 \\
\hline BMI, $\mathrm{kg} / \mathrm{m}^{2}$ & $25.3+/-4.9$ & $25.4+/-5.1$ & $25.9+/-3.1$ & 0.900 \\
\hline ASA I-II/III/IV, n & $127 / 109 / 8$ & $117 / 101 / 7$ & $10 / 8 / 1$ & 0.113 \\
\hline Familial disease, $\%$ & $35(14.3)$ & $35(15.6)$ & $0(0)$ & 0.063 \\
\hline Tumor side (right/left) & $134 / 110$ & $120 / 105$ & $14 / 5$ & 0.087 \\
\hline Tumor size, mm & $43.9+/-20.3$ & $43.4+/-20.4$ & $50.2+/-22.8$ & 0.162 \\
\hline$<5 \mathrm{~cm} / \geq 5 \mathrm{~cm}, \%$ & $151(62) / 92(38)$ & $143(64) / 81(36)$ & $8(42) / 11(58)$ & 0.061 \\
\hline$<6 \mathrm{~cm} / \geq 6 \mathrm{~cm}, \%$ & 199(82) / 44(18) & $186(83) / 38(17)$ & $13(68) / 6(32)$ & 0.123 \\
\hline \multicolumn{5}{|l|}{ Comorbidities, \% } \\
\hline CAD & $29(11.9)$ & $25(11.1)$ & $4(21.1)$ & 0.199 \\
\hline Diabetes mellitus & $63(25.8)$ & $58(25.8)$ & $5(26.3)$ & 0.959 \\
\hline Previous stroke & $10(4)$ & $9(4.0)$ & $1(5.2)$ & 0.790 \\
\hline Previous MI & $20(8.2)$ & $17(7.6)$ & $3(15.8)$ & 0.209 \\
\hline $\mathrm{PAH}$ & $2(0.8)$ & $0(0)$ & $2(10.5)$ & $<0.001$ \\
\hline $\begin{array}{l}\text { Antihypertensive } \\
\text { medications before PMP, } n\end{array}$ & $1+/-1.1$ & $0.95+/-1.1$ & $1.31+/-1.1$ & 0.175 \\
\hline \multicolumn{5}{|l|}{ Clinical signs, \% } \\
\hline Sweating & $84(34.4)$ & $78(34.7)$ & $6(31.6)$ & 0.786 \\
\hline Headaches & $72(29.5)$ & $67(29.8)$ & $5(26.3)$ & 0.751 \\
\hline Palpitations & $94(38.5)$ & $90(40.0)$ & $4(21.1)$ & 0.103 \\
\hline Hypertension & 180(73.7) & $164(72.9)$ & $16(84.2)$ & 0.281 \\
\hline
\end{tabular}

Mean+/- standard error or $\mathrm{n}(\%)$; BMI : body mass index ; ASA : American Society of Anesthesiologists Score ; CAD : coronary artery disease ; MI : myocardial infarction ; $\mathrm{PAH}$ : pulmonary arterial hypertension ; PMP : preoperative medical preparation 
Table 2: Preoperative medical preparation (PMP) before adrenalectomy and intraoperative data

\begin{tabular}{|c|c|c|c|c|}
\hline & $\begin{array}{c}\text { Total } \\
(n=244)\end{array}$ & $\begin{array}{l}\text { No conversion } \\
\qquad(n=225)\end{array}$ & $\begin{array}{c}\text { Conversion } \\
\qquad(n=19)\end{array}$ & $\mathbf{p}$ \\
\hline Type of PMP & & & & 0.863 \\
\hline Alpha blocker no selective, $\%$ & $65(27)$ & $59(26)$ & $6(32)$ & \\
\hline Alpha blocker selective, $\%$ & $52(21)$ & $49(22)$ & $3(16)$ & \\
\hline CC-B, \% & 119(49) & 110(49) & $9(47)$ & \\
\hline None, \% & $8(3)$ & $7(3)$ & $1(5)$ & \\
\hline Number of medications for PMP, $n$ & $1.14+/-0.5$ & $1.15+/-0.5$ & $1.05+/-0.4$ & 0.374 \\
\hline Need for preoperative hospitalisation, \% & $79(32.4)$ & $69(30.7)$ & $10(52.6)$ & 0.049 \\
\hline Surgical approach & $192 / 52$ & $177 / 48$ & $15 / 4$ & 0.977 \\
\hline (Trans / Retro), \% & $(78.6 / 21.3)$ & $(78.7 / 21.3)$ & $(78.9 / 21.1)$ & \\
\hline Operative duration, $\min$ & $134+/-57$ & $129+/-55$ & $196+/-45$ & $<0.001$ \\
\hline Anesthesia duration, $\min$ & $215+/-69$ & $210+/-67$ & $279+/-65$ & $<0.001$ \\
\hline
\end{tabular}

Mean+/- standard error or $\mathrm{n}(\%)$; PMP : preoperative medical preparation ; CC-B : calcium channel blockers ; Trans : transperitoneal laparoscopic approach, Retro : retroperitoneal laparoscopic approach 
Table 3: Preoperative biological markers profile *

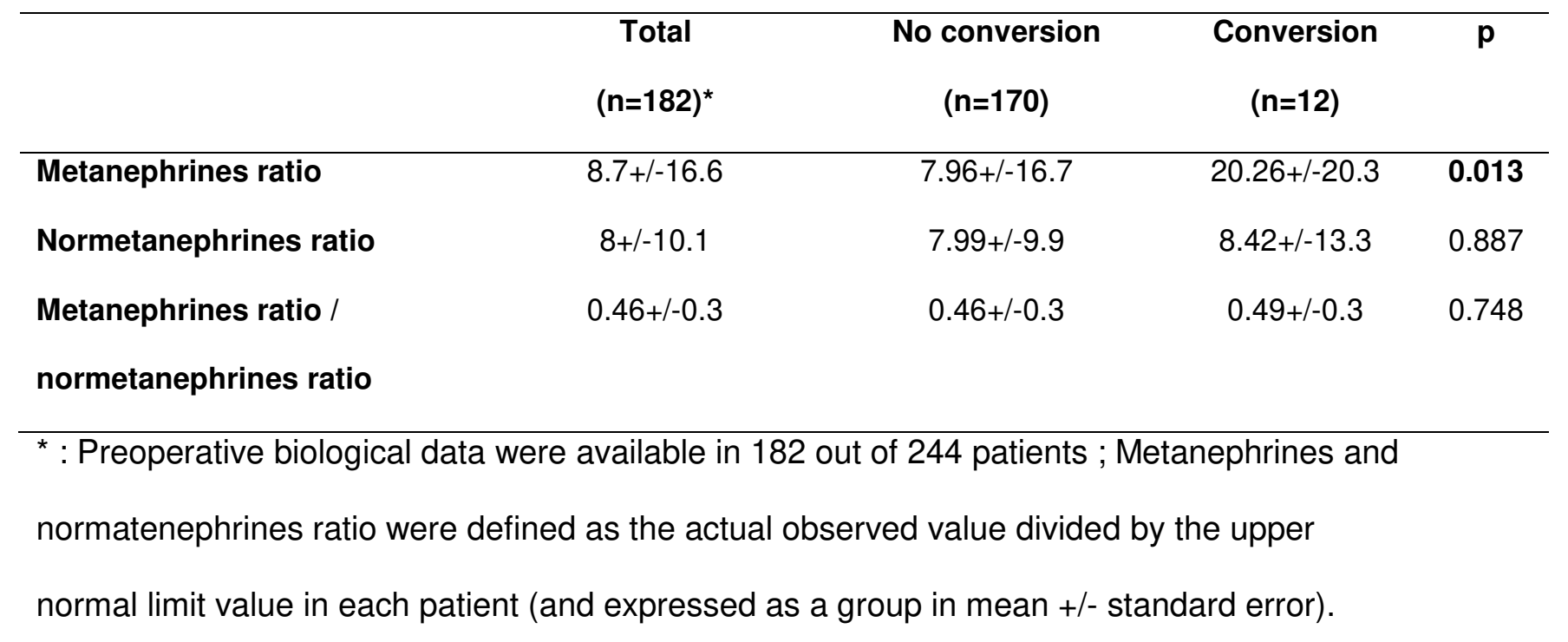

Table 4 : Preinduction hemodynamic data

\begin{tabular}{lcccc}
\hline & $\begin{array}{c}\text { Total } \\
(\mathbf{n}=\mathbf{2 4 4})\end{array}$ & $\begin{array}{c}\text { No conversion } \\
(\mathbf{n = 2 2 5})\end{array}$ & $\begin{array}{c}\text { Conversion } \\
(\mathbf{n = 1 9 )}\end{array}$ & $\mathbf{p}$ \\
\hline MBP, $\mathbf{m m H g}$ & $99.9+/-15$ & $99.9+/-15$ & $100+/-12$ & 0.857 \\
MBP $<\mathbf{1 0 0} \mathbf{m m H g}, \%$ & $130(55)$ & $119(54)$ & $11(65)$ & 0.408 \\
BP $<\mathbf{1 3 0 / 8 5} \mathbf{m m H g}, \%$ & $122(52)$ & $113(52)$ & $9(53)$ & 0.915 \\
Lowest DBP, $\mathbf{m m H g}$ & $77+/-14$ & $77+/-14$ & $80+/-10$ & 0.448 \\
Greatest DBP, $\mathbf{m m H g}$ & $84+/-16$ & $84+/-16$ & $84+/-13$ & 0.985 \\
Mean DBP, $\mathbf{m m H g}$ & $80+/-13$ & $80.3+/-14$ & $82+/-9$ & 0.703 \\
Lowest SBP, $\mathbf{m m H g}$ & $134+/ 23$ & $134+/-23$ & $136+/-23$ & 0.730 \\
Greatest SBP, $\mathbf{m m H g}$ & $144+/-25$ & $144+/-25$ & $142+/-25$ & 0.724 \\
Mean SBP, $\mathbf{m m H g}$ & $139+/-22$ & $139+/-22$ & $139+/-23$ & 0.977 \\
\hline
\end{tabular}

MBP : mean arterial blood pressure ; BP : blood presure ; DBP : diastolic blood pressure ; SBP : systolic blood pressure ; Mean+/- standard error or n (\%) 
Table 5 : Intraoperative hemodynamic data

\begin{tabular}{|c|c|c|c|c|}
\hline & $\begin{array}{c}\text { Total } \\
(n=244)\end{array}$ & $\begin{array}{c}\text { No } \\
\text { conversion } \\
(n=225)\end{array}$ & $\begin{array}{l}\text { Conversion } \\
\qquad(n=19)\end{array}$ & p \\
\hline Greatest MBP, mmHg & $131+/-29$ & $131+/-29$ & $130+/-27$ & 0.941 \\
\hline Lowest MBP, mmHg & $61+/-14$ & $61+/-14$ & $64+/-13$ & 0.442 \\
\hline Mean MBP, mmHg & $96+/-14$ & $96+/-14$ & $97+/-10$ & 0.750 \\
\hline Greatest DBP, mmHg & $103+/-25$ & $103+/-25$ & $102+/-21$ & 0.816 \\
\hline Lowest DBP, mmHg & $49+/-13$ & $49+/-14$ & $50+/-10$ & 0.818 \\
\hline Mean DBP, mmHg & $76+/-13$ & $76+/-13$ & $76+/-10$ & 0.912 \\
\hline Greatest SBP, mmHg & $188+/-45$ & $188+/-45$ & $188+/-43$ & 0.906 \\
\hline Lowest SBP, mmHg & $86+/-20$ & $85+/-19$ & $92+/-21$ & 0.165 \\
\hline Mean SBP, mmHg & $136+/-22$ & $136+/-22$ & $140+/-15$ & 0.456 \\
\hline $\mathrm{SBP}>200 \mathrm{mmHg}, \%$ & $81(33)$ & $74(33)$ & $7(37)$ & 0.746 \\
\hline $\mathrm{SBP}>160 \mathrm{mmHg}, \%$ & $169(69)$ & $155(69)$ & $14(74)$ & 0.683 \\
\hline $\mathrm{SBP}>200 \mathrm{mmHg}, \mathrm{min}^{\star}$ & $0(0-125)$ & $0(0-90)$ & $0(0-125)$ & 0.007 \\
\hline $\mathrm{SBP}>160 \mathrm{mmHg}, \mathrm{min}^{\star}$ & $10(0-140)$ & $10(0-140)$ & $20(0-110)$ & 0.005 \\
\hline SBP > $30 \%$ baseline, $\mathrm{min}^{\star}$ & $0(0-130)$ & $0(0-75)$ & $0(0-130)$ & 0.005 \\
\hline SBP $\leq 30 \%$ baseline, $\min ^{\star}$ & $10(0-170)$ & $10(0-170)$ & $7.5(0-45)$ & 0.393 \\
\hline MBP $<60 \mathrm{mmHg}$ duration, min & $0(0-74)$ & $0(0-74)$ & $0(0-25)$ & 0.441 \\
\hline HD instability (\%) & $88(36)$ & $81(36.1)$ & $7(36.8)$ & 0.953 \\
\hline Intraoperative infusion, $\mathrm{mL}$ & $3328+/-1628$ & $3204+/-1553$ & $4776+/-1835$ & $<0.001$ \\
\hline Vasopressives drugs (n) & $1.5+/-1.3$ & $1.5+/-1.3$ & $1.5+/-1.3$ & 0.744 \\
\hline Vasopressives drugs (\%) & $186(76)$ & $171(75)$ & $15(79)$ & 0.772 \\
\hline Duration $\mathrm{HR}<50$, $\min ^{*}$ & $0(0-115)$ & $0(0-110)$ & $0(0-115)$ & 0.041 \\
\hline Lowest HR, beats/min & $58.9+/-12.5$ & $58.6+/-12.6$ & $62.7+/-11.2$ & 0.171 \\
\hline Duration HR>110, min* & $0(0-140)$ & $0(0-130)$ & $0(0-140)$ & 0.095 \\
\hline Higher HR, beats/min & $98.8+/ 22.5$ & $98.9+/-22.4$ & $97.7+/-24.5$ & 0.819 \\
\hline
\end{tabular}

Mean+/- standard error or $\mathrm{n}(\%) ;{ }^{*}$ : median (range) ; MBP : mean arterial blood pressure ; BP : blood pressure ; DBP : diastolic blood pressure ; SBP : systolic blood pressure ; HD instability : Hemodynamic instability ; Intraoperative infusion: intraoperative infusion of crystalloids and/or colloids in $\mathrm{mL}$; HR : heart rate 
Table 6: Postoperative complications after unilateral adrenalectomy

\begin{tabular}{|c|c|c|c|c|}
\hline & $\begin{array}{l}\text { Total } \\
(\mathrm{n}=\mathbf{2 4 4})\end{array}$ & $\begin{array}{l}\text { No conversion } \\
\qquad(n=225)\end{array}$ & $\begin{array}{l}\text { Conversion } \\
\qquad(n=19)\end{array}$ & $\mathbf{p}^{*}$ \\
\hline Hospitalization duration (days) & $6.0+/-3.7$ & $5.6+/-3.1$ & $11.5+/-5.6$ & $<0.001$ \\
\hline Reoperation (\%) & $2(0.82)$ & $1(0.04)$ & $1(5.20)$ & 0.025 \\
\hline CV morbidity (\%) & $14(5.7)$ & $11(4.9)$ & $3(15.8)$ & 0.049 \\
\hline Clavien II-V morbidity (\%) & $28(11.5)$ & $22(9.8)$ & $6(31.6)$ & 0.004 \\
\hline Clavien classification (\%) & & & & 0.001 \\
\hline I & $14(5.7)$ & $14(6.2)$ & $0(0)$ & \\
\hline II & $23(9.4)$ & $18(8)$ & $5(26.3)$ & \\
\hline IIIB & $1(0.4)$ & $0(0)$ & $1(5.2)$ & \\
\hline IV & $3(1.2)$ & $3(1.3)$ & $0(0)$ & \\
\hline IVB & $1(0.4)$ & $1(0.44)$ & $0(0)$ & \\
\hline No morbidity (\%) & 202(83) & $189(84)$ & $13(68)$ & \\
\hline
\end{tabular}

Mean+/- standard error or $n(\%)$ 